discussed by Ferrel, that in every case the latest and most accurately determined physical constants are used, and that the theoretical deductions, while simply offered as such to be tested, are strictly the results of mathematical analyses. If in time these appear inadequate, the measure of praise for the man and his work may be diminished, but only in proportion as it is remembered that meteorological data and laws were in a condition more or less chaotic when he took up bis labor of developing these into a consistent harmonious science.

Washington, D.C., Jan. 9.

Alexander McAdie.

\section{Cyclones and Areas of High Pressure.}

I HAD supposed that Professor Davis would give some explanation of the argument against the condensation theory of cyclones deduced from the comparisons of the temperatures in cyclones with those in high-pressure areas. He commences with a citation from my book, in which $I$ state that the high pressures in the north-west sides of cyclones in the higher latitudes in winter are caused mostly by their lower temperatures, and consequently greater densities. He thinks the high pressure over the Alps in November, 1889, is a typical case of all such high-pressure areas. While I do not so regard it, yet, for the sake of brevity, I will here concede it, and consider merely this supposed typical case. Over the Alps, during the last five of the fourteen days of the existence of this high pressure, the temperature on the summits of the Alps was found to be several degrees warmer than the normal temperature of the season. There are no observations to show how high this abnormal temperature extended, but I am willing to admit that it may have extended up to a considerable altitude. Professor Davis, because this temperature is found to be above the normal a few degrees, maintains that the descent of the air is not due to its being heavier than the surrounding air, thus assuming that the surrounding temperatures at a distance at the time are the same as the normal temperature, notwithstanding the wellknown great and long-continued departures from the normals which frequently occur over large areas of the country. But it is not necessary that this body of heated air in high-pressure areas should have a temperature lower than the surrounding temperatures even; for if the great vertical extent of air above it has a temperature only one or two degrees lower than the surrounding temperatures on the same levels, which gives rise to a descending current, the air below, if it even has a little higher temperature than the surroundings, cannot rise up through the descending current, but must be forced downward. But suppose it were clearly established that the air in a high-pressure area extending hundreds of miles had a lower temperature than the surroundings even, and not merely the normal of the season: how is the greater pressure and the descent of the air to be accounted for? Professor Davis has nerer hinted at a probable explanation merely. The deduction, therefore, from a few surface observations merely in a very limited region, that the air over a large area, and extending to the top of the atmosphere, is warmer than the surrounding air at a great distance in all directions, especially where these few observations are found to give a temperature above the normal merely, and not above the surrounding temperatures at the same levels, should be received with greatcaution; for, if there were even a well-established theory to account for the descent of the air under these circumstances, these observations could scarcely be regarded as having any weight in confirmation of such a theory.

In what precedes I have gone upon the assumption that a lower temperature is the only cause of the descent of the air in highpressure areas. While I regard this as adequate to account for it, I have never said or thought that it is the only cause, but simply the principal cause. I think there are other causes, especially in the origin of these high-pressure areas, which, for our present purpose, it is not necessary to discuss here.

Professor Davis says, "Records of temperature made on high mountain-peaks furnish the best means of testing the convectional theory of cyclones, for, even if all other tests were successfully borne, failure under this test would be fatal to the theory." By
" convectional theory of cyclones" I understand him to mean the condensation theory, which requires the air in the ascending current to be warmer and lighter than that of the surroundings at the same levels. Now, this theory can neither be established nor overthrown by any such tests. Cyclones are usually several hundred, sometimes a thousand and more, miles in diameter; and to prove that the air over so large an area up to the top of the atmosphere, or at least up to high altitudes, has a higher or a lower temperature than its surroundings, would require numerous stations of observation at many different levels, not only over this large area, but also all around this area at great distances. The condensation theory requires that the temperature of the air in a cyclone must be greater, in a general way, than that of the surrounding air; but this does not mean that there are no places within the cyclone, especially on the earth's surface, with lower temperatures than those of many places outside. In the theoretical treatment of a cyclone we have necessarily to assume certain regular conditions of uniform temperature at the same distances in all directions; but I have always been careful to explain that such conditions are never found in nature, but generally only rough approximations. In a large cyclone there is a great difference between the north and south sides, due to difference of latitude, which is taken into account in the general motions of the atmosphere, and so must be excluded in the treatment of the cyclones, and the differences of temperature only with reference to corresponding temperatures outside of the cyclone on the same latitudes must be considered. Besides, the temperatures vary all around the cyclone, not only on account of difference of latitude, but likewise from various abnormal causes. It must be expected, therefore, in comparing inside temperatures with the surrounding ones, especially surface temperatures, that there would be numerous cases in which those within would be found lower than many of those in the surroundings. The theory only requires that there shall be a predominance of higher temperatures in the interior. Besides, the conditions of a cyclone need not extend down to the surface at all, and, in fact, mere surface conditions generally have little or nothing to do with a cyclone. If the necessary conditions exist at altitudes only considerably above the earth's surface, the air is thrown into a great whirl or gyration, which relieves the air below of a part of the pressure upon it, and increases the pressure round about; so that this air tends to rise up, just as the water does in a suction-pump, and the surrounding air flows in to take its place; and in flowing in it assumes a gyratory motion, not only from the deflecting force of the earth's rotation, but likewise from the action of the air above by means of friction, so that it is brought into the general vertical and gyratory circulation. But suppose that it could be shown that the air in a cyclone is mostly or entirely of a lower temperature than the surrounding air at all altitudes, and yet ascends, as it always does: how is this strange phenomenon to be accounted for when there is no force, either real or imaginary, to cause it to ascend?

Professor Davis thinks that the snow-fall on the Alps at the time of the cyclone of Oct. 1, 1889, had little effect in lowering the temperature, on. account of the wind; but this is one of the causes which Dr. Hann gave, a few years ago, of the lower surface temperatures in cyclones. The air, in being forced up the mountains on the windward side, is expanded and cooled below the temperature of the air generally on the same level. Another reason which he assigned was, that as the lowest pressure above lags behind that below, as was shown by Loomis, and first explained, I think, by Dr. Hann, the cold north - westerly winds set in above rather before the lowest pressure-point is passed. The real centre of the cyclone above is not that of lowest pressure.

I admit that it is not strictly logical to assume that two theories, or two kinds of forces, may not be such as to give the same effects, especially where nothing is known of the nature or manner of application of the one kind; but still this is extremely improbable. As the general motions of the atmosphere, cyclones, and tornadoes, are all very much alike, consisting of gyrations around a centre, - and it is admitted that in the first and last the air rises where it is warmest and lightest and because this is so, and that this is even the case with cyclones in the lower latitudes, - we should besitate in making an exception in the case 
of cyclones in the higher latitudes, because a few surface observations merely of temperature, which, as has been shown. I think, should have no weight, seem to indicate that the complete conditions of a cyclone, upon the condensation theory, do not exist.

Mr. Clayton, in his communication, sets out in a very com mendable way by discarding mere authority in scientific questions. He, however, proceeds to give two columns of citations from different authorities. But the most of this is entirely proper; for we have to depend more or less upon authority for observational data, and it is only where the decision of a question depends merely upon the use and application of scientific principles that mere authority should be discarded. All observations, however, should be well considered and weighed, especially where they seem to conflict with well-establisherl scientific principles. I have been familiar with all of Loomis's meteorological papers, and I do not call to mind any cases in which his results deduced directly from observation seened to be in conflict with any theories which I have adrocated, but of course there are some things which I cannot satisfactorily explain. I have always made numerous quotations from Loomis's papers in confirmation of my theories It is a little singular, however, that Mr. ('layton should cite some of the same things against me. From some of Loomis's theoretical deductions from the observations I dissent.

With regard to the comparisons of observations at Denver and Pike's Peak, both merely surface observations at a long distance apart, in order to show whether the air is in a state of stable or unstable equilibrium over an area hundreds of miles in diameter, it is not necessary for me to add any thing more to what $I$ have already stated on that subject. These cases were mostly in the summer season, when mountain-peaks are cooler than the surrounding air at a distance, and when lowland stations are abnormally heated, and the rertical temperature gradient, for some distance from the surface, large. If the lower temperatures had been taken a little above the surface, and compared with one vertically above it, no unstable state, probably, would have been indicated when, as is stated, no extraordinary disturbances occurred. The reason why most of these cases of unstable, and approximately unstable, states occurred in May, I have explained in my book. Whether heated dry air has much ascensional force depends upon the state of the air. In the stable state it can only ascend until it becomes cooled down to the temperature of the surrounding air at a distance on the same levels. In the unstable state, the higher it ascends, the warmer it becomes relatively to the surrounding air ; and so, of course, it rushes up with great violence until the stable state is again restored.

The fact which Loomis has established, and which is a matter of common observation, that very heavy rains do not continue very long, is very reasonable; for the more rapidly the store of energy in the uncondensed vapor is spent, the sooner, of course, must the store of energy become exhausted.

I have been at great pains to show that the unstable state, which gives rise to cyclones and tornadoes, may be induced in perfectly dry air ; and I have cited Loomis in conformation of this, when he shows that cyclones of moderate barometric depression in the centre, and without any violence, do exist. But $\mathrm{Mr}$. Clayton brings in the same thing against the condensation theory, under the impression, I suppose, that, because I call the theory of cyclones the condensation theory in deference to Espy, I consider vapor and its condensation entirely indispensable. The vapor is a very essential part, and without it cyclones would, no doubt, be of much less frequent occurrence, and would have little violence. Loomis has shown that when there are cyclones in dry weather, with little or no rain, the depressions are small. These take place mostly in the summer season, when the air over a large area becomes much heated: and although the ascent of air over this region is not sufficient to give rise to much rain, or even cloudiness perhaps. yet it is sufficient to cause haziness in the atmosphere, in which state the heat energy is absorbed directly from the sun's rays, instead of getting it indirectly from condensation after it has been absorbed in evaporation. Mr. Clayton cites a number of authorities to show that there is a body of warm air, a little above the earth's surface, in areas of high pressure, and that the vertical temperature gradient here is small, much less often than in cyclones. I have never denied this. It is simply storming a camp in which I am not to be found. More than six years ago, in "Recent Advances in Meteorology," I gave seven cases of this sort, one in which detailed observations were given to show that the vertical temperature gradient may become in rerted. The same is given in my recent work.

Mr. Clayton thirks that Dr. Hann's recent investigations of cyclones in the Alps should add a link to the chain of evidence that the temperature of the air-column as a whole is lower in cyclones than in the surrounding air ; but, if this is even admitted, where are the other links? So far as I can see, they all seem to be "missing links." He also gives his views with regard to various other things, which is well enough if they are not intended as arguments, and they do not seem to be. But still it is of much more importance to know what he can prove and establish than to know what he thinks. He thinks that mechanical action has much to do with the origin of storms; but what this means, I am unable to say. The mere origin of a cyclone, although of importance, is of little importance in comparison with the great question of where the energy comes from to support the cyclone after it has been originated.

Finally, Mr. Clayton proposes three questions for my answer. To the first and second I answer emphatically, "No." If Mr. Claston thinks that a cyclone can originate and be maintained in this way, let him show in what way. But let him remember that he is not to commence with his high areas and his troughs, for this is not a normal condition of the atmosphere, but let him first account for these. and then proceed to show how the air in flowing into his trough is thrown into a gyration; and as the air in this area of gyration, according to the new theory, is heavier than the surrounding air, and at the same time rises up, let him especially show where the energy comes from to support the gyration and force up the heavier air in the interior. I do not say that in such a case there would not be a certain very small amount of gyratory morement produced by the flowing of the air into the trough while it was being tilled up, as it would be at once if there were no restraining force to keep the air from the high pressures on each side from rushing in. But such highpressure areas continue often a long time, and do not fill up the troughs : and the question is, what maintains them? I have fully explained all this at various times upon my principles, and I now leave it to him to explain upon his. I commence with a normal state of air without high-pressure areas and troughs of low pressure, and show how the unstable state is induced, how from this the cyclone originates, and how the gyrations cause a wave of high pressure all around, and, where there are two cyclones, how the ridge of high pressure between is caused. The low-pressure between two cyclones, together with other irregularities of pressure, permanent or otherwise, in some rare cases, gives a very oblong low-pressure area, or trough. Mr. Clayton proceeds in the reverse order, and commences with the high pressures without first accounting for them, which he makes a basis of his whole process. The world is supported upon the shoulders of Atlas, and Atlas upon the back of a tortoise ; but the question still arises, upon what does the tortoise stand? Let Mr. Clayton first show upon what his tortoise stands.

With regard to Mr. Clayton's last question, I know nothing with regard to the circumstances of the cyclone to which he refers. It was in the winter, when surface temperatures are very low, and vertical temperature gradients small, and even reversed sometimes near the earth's surface. This, however, does not affect the gradient, estimated from a little distance above the earth; but I have said so much with regard to the inadequacy of a few surface observations at the bottom of the great ocean of atmosphere to prove that the air, or no part of it above, is not warmer than the surrounding air, all of which is just as pertinent in this case, that certainly nothing more can be required. As I have said before, the mere surface condition may have little or nothing to do with a cyclone. But suppose I cannot explain it, as Mr. Clayton seems to think, "upon the assumption of a higher mean temperature of the air-column within the field of the cyclone :" how does he explain it upon the assumption of a lower mean temperature and heavier air-column? He proposes his question with an 
air which would indicate that he had completely explained the phenomenon upon his theory, whereas there has nerer been even an attempt made to explain any thing by it.

The law of gravitation, suggested by the fall of an apple, was withheld by Newton for a number of years, because, on account of incorrect data, it was not confirmed by observation. With the reserve and caution characteristic of a true philosopher, he thought it should be fully tried and tested first. But now we have a theory thrust upon us for our assent which has not been developed, and applied in the explanation of a single phenomenon in the local disturbances of the atmosphere; and yet I am censured for thinking that there has been entirely too much haste in the matter, and that it should first have been shown that it will at least account for a few of the observed atmospheric phenomena. Let the adrocates of this theory, if it can be so called, take up the matter now, and show that it accounts for the phenomena as well as, or better than, the condensation theory. Let them give me a chance to look into the workings of this new theory.

WM. FERREL.

Martinsburg, W. Va., Jan. 10.

\section{BOOK-REVIEWS.}

Tyeho Brahe: a Picture of Scientific Life aud Work in the Sixteenth Ceutury. By J. L. E. Dreyer. Edinburgh, Adam $\&$ Charles Black. $8^{\circ}$. (New York, Macmillan, \$3.30.)

THIs is a work of much value to students of the history of science. Tycho Brahe holds a prominent place in the annals of astronomy; and he was, moreover, a inember of the Danish nobility and a man of considerable means, with a wide circle of acquaintances and many opportunities for travel. Hence his life was more dramatic and fuller of incident than the lives of scientific men usually are; and Professor Dreyer has here related it in an interesting way. The book is well written, with great care in collecting and sifting the facts, and with an evident desire to be just to all parties. The early life and studies of Tycho are described somewhat briefly ; but a full account is given of his early attempts at astronomical observation and of the endow ments given bim by King Frederick II. to enable him to pursue his chosen work. The Island of Hveen, which was assigned him to hold during the king's pleasure, became the scene of his most inportant discoveries; and the income it afforded, together with certain other revenues placed at his disposal by his royal friend and patron, enabled him to hire assistants and to prosecute his work vigorously for many sears. But after the death of Frederick the authorities were less favorable to Tycho ; so that at last his endowments were taken from him, and he left Denmark for a new field of labor under the German emperor at Prague. Professor Dreyer gives a very good description of the Island of Hveen, and the facilities available there for astronomical work, and then endeavors to explain how and why Tycho Brahe lost his position there, - a misfortune due quite as much to Tycho's own faults as to the disfavor of the authorities. His new station at Prague is also well described ; and one of the most interesting passages in the book is that relating the meeting of the veteran Tycho with the young Kepler, an event of such significance in the development of science. Indeed, this meeting was the most important result of Tycho's residence at Prague, which was soon terminated by his death in his fifty-fifth year.

Of Tycho Brahe's scientific achievements, Professor Dreyer gives a full and detailed account. $\mathrm{He}$ was an observer rather than a thinker, and his biographer thinks that his observations could hardly have been surpassed in accuracy but for the invention of the telescope. The instruments he employed, many of which were devised by him, are described with some minuteness, and the importance of his observations as a basis for the theories of Kepler and Newton is clearly shown. Tycho's most important labors, in Professor Dreyer's opinion, were those relating to the

\section{LONGMANS, GREEN \& CO. HAVE NOW READY:}

The First Crossing of Greenland. By Dr. FRIDTJOF NANSEN. Translated from the Norwegian by Hubert Majendie (depp, B A, Lec
turer at the University of Upsala. With 5 Maps, turer at the University of Upsala. With 5 Maps, 12 full page plates, and 157 Illustrations in the
Text. A Preface by J. Scott Keltie, Libriarian of the Royal Gengraphical Society. \& volumes, ornamental cloth cover, silvered top, $8 \mathrm{vo}, 1,040$ pages $\$ 10.50$.

"A graphic and animated recital of the first cross ing of Greenland, translated admirably into English from the Norwegian. Both volumes are handsomely printed and profusely illustrated, the camera carried by the explorer having been used with excellent effect."-N.Y. Times.

II.

Political Americanisms.

A Glossary of 'Terms and Phrases Current at Differi ent Periods in American Politics.

By CHARLES LEDYARD NORTON, 16mo, ornamental cloth cover, $\$ 1.00$

"So fully does this book fill a vacant place in politico historical literature, that it is hard to understand why it has only just appeared. . . . A book so complete that the reader must have a long and quick memory to discover what may be lacking. short; the work has been done so thoroughly in keeping with the true spirit of dictionary-makin thor's own politics." $-N$. Y. Herculd.

III.

The Cruise of the "Alerte"; The Narrative of a Search for Treasure on the Des ert Island of Trinidad.

By E. F. KNIGH'T, Author of "The Cruise of the Falcon." With 18 Plates, 5 Woodcuts in the text, w 8 \%o, $\$ 3.50$

For sale by all booksellers. Sent on receipt of price by the publishers,

LONGMANS, GREEN \& CO., 15:East Sixteenth Street, New York.

\section{A SYSTEM OF EASY Hy J. H. Crom w whL, Ph. Is. Twenty six different forms of Alphabets. The space to be lettered is divided into squares. and and inked. Price, 50 cents, postpaid. \\ E. \& F. N. SPON, 12 Cortlandt Street, New York.}

\section{P R A C T C A L BOOKS}

\section{F UBWET HA ND STA} wing in a simple manner how to make Rubber Hand Stamps, Rubber Stereotype Plates, and also substitutes to be used for the same, including the Hektograph; together with a description F ully Illustrated. Price $\$ 1.00$.

ARITHM ETIC OF ELECTRICITY. By T. O'Conor Sloane, A.M., E.M., Ph.D

This work gives Electric Calculations in such a simple manner that it can be used by any one having a knowledge of Arithmetic. It treats of calculations for wiring; resistance in general, arrangement of batteries for different work, and is supplemented by the most practical series of tables ever published. It is absolutely indispensable to the practical electrician, as well as to the amateur. $\$ 1.00$.

Send for our large catalogue, embracing works on more than fifty subjects. We mail it free to any address. NORMAN W. HENLEY \& C0., Publishers, Importers and Booksellers, 150 Nassau St., N. Y.

WHILE ${ }_{\mathrm{IN}}^{\text {CLASES }}$ BOTANY

are forming and the question of suitable text books in this fascinating study is under consideration, the progressive teacher consults the AMERICAN MOGK COMPANY'S list and finds therein a most attractive array of standard and popular Botanical works. The authors who have contributed to the Botanical department of the Company's library are such well-known educators and scientists as Bentley, Coulter, Gray, Goodale, Herrick, Hooker, Stule, Wood, and Youmans, and their works cover the whole field from the elementary class to the high school, academy and college, besides furnishing valuable material, presented in popular style, for the private student and general scientific reader.

Teachers and school officers who are looking for the best text books on Botany, or on any other subject should send for the American Book Company's Catalogue of over 2,000 School and College Text Books. It will be sent free, postpaid, to any address upon application to the

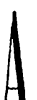

